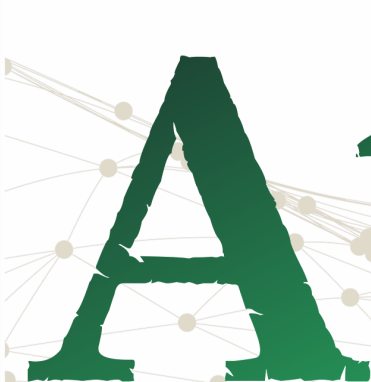

ISSN n०2526-8031

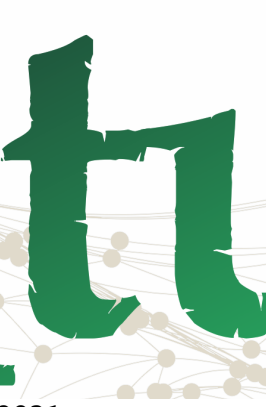

tur

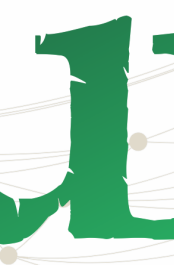

11

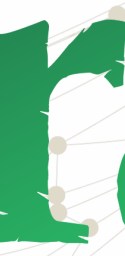

rá

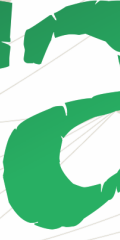

á

Pan-Amazônica

de Comunicação

Vol. 4, n. 3, Setembro-Dezembro. 2020

\title{
A TRAJETÓRIA DO TELEJORNALISMO NO TOCANTINS: UM OLHAR SOBRE O PERCURSO HISTÓRICO
}

The trajectory of TV journalism in Tocantins: a look at the historical route.

La trayectoria del tele periodismo en Tocantins: una mirada a la ruta histórica.

\section{Adriano Nogueira da Fonseca ${ }^{1}$}

\section{RESUMO}

O artigo ressalta a importância de estudar a trajetória do telejornalismo brasileiro destacando a chegada e o avanço da televisão no Tocantins, o Estado mais novo do país. A influência política para a instalação de emissoras no Estado criado no fim da década de 1980 e os desafios tecnológicos impostos pela distância dos grandes centros. O espelho da realidade à época, com a cessão de áreas para que torres de transmissão fossem erguidas e a permuta de incentivos por comerciais televisivos. $O$ estudo aborda a história das mídias audiovisuais com destaque à expansão das emissoras da TV Anhanguera, afiliada da TV Globo, formas de produção de conteúdo, consumo de notícias, além de resgatar a narrativa da linguagem e, espera-se com isso, contribuir com as pesquisas relacionadas ao telejornalismo regional e ao ensino do jornalismo.

PALAVRAS-CHAVE: Mídias Audiovisuais. Televisão. Telejornalismo. História. Tecnológicos.

\section{ABSTRACT}

The article highlights the importance of studying the trajectory of Brazilian television news, highlighting the arrival and advance of television in Tocantins, the country's newest state. The political influence for the installation of broadcasters in the State created in the late 1980 s and the technological challenges imposed by the distance from large centers. The mirror of reality at the time, with the assignment of areas for transmission towers to be

\footnotetext{
${ }^{1}$ Mestrando em Comunicação e Sociedade pelo Programa de Pós-Graduação da Universidade Federal do Tocantins. Possui graduação em Comunicação Social: Habilitação em Jornalismo pela Universidade do Tocantins (2002). É especialista em Comunicação, Sociedade e Meio Ambiente pela Universidade Federal do Tocantins (2008). Tem experiência na área de Comunicação, com ênfase em Telejornalismo. Atualmente é Chefe de Redação da TV Anhanguera - TO. e-mail: adriano.tv@gmail.com;
} 


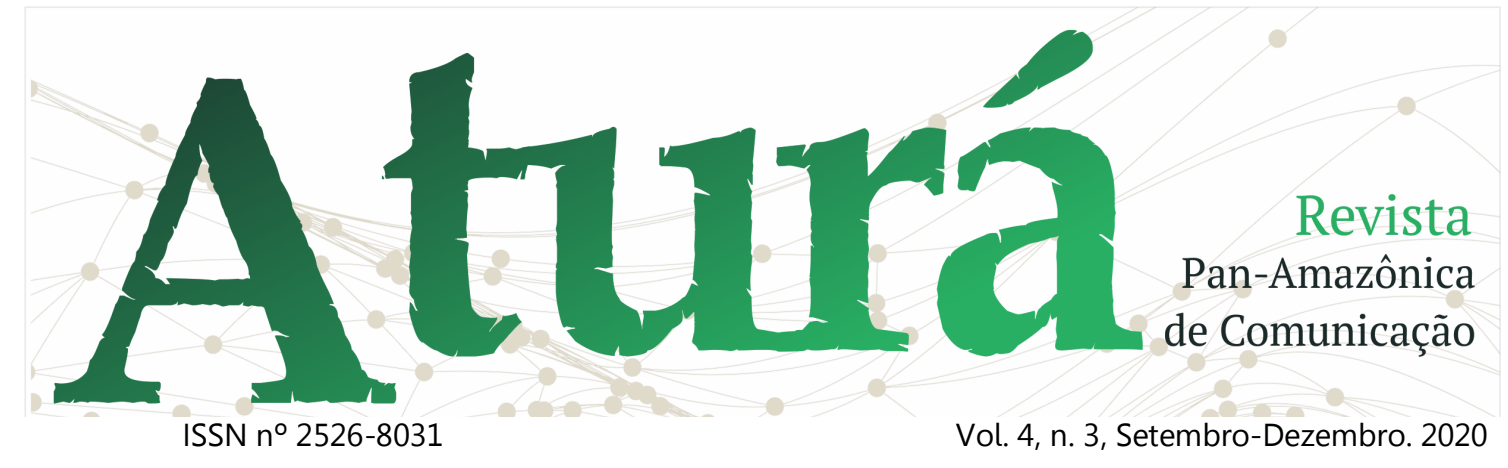

erected and the exchange of incentives for television commercials. The study addresses the history of audiovisual media with emphasis on the expansion of TV Anhanguera stations, affiliated with TV Globo, ways of producing content, consuming news, in addition to rescuing the narrative of language and, hopefully, contributing to research related to regional television news and journalism teaching.

KEYWORDS: Audiovisual Media. Television. TV journalism. History. Technological.

\section{RESUMEN}

El artículo destaca la importancia de estudiar la trayectoria de los informativos de la televisión brasileña, destacando la llegada y avance de la televisión en Tocantins, el estado más nuevo del país. La influencia política para la instalación de locutores en el Estado creada a fines de la década de los ochenta y los desafíos tecnológicos que impone el alejamiento de los grandes centros. El espejo de la realidad de la época, con la asignación de áreas para la construcción de torres de transmisión y el intercambio de incentivos por comerciales de televisión. El estudio aborda la historia de los medios audiovisuales con énfasis en la expansión de las estaciones de TV Anhanguera, afiliadas a TV Globo, formas de producir contenidos, consumir noticias, además de rescatar la narrativa del lenguaje $y$, con suerte, contribuir a la investigación relacionada con la televisión regional Enseñanza de noticias y periodismo.

PALABRAS CLAVE: Medios audiovisuales. Televisión. Teleperiodismo. Historia. Tecnológico. 


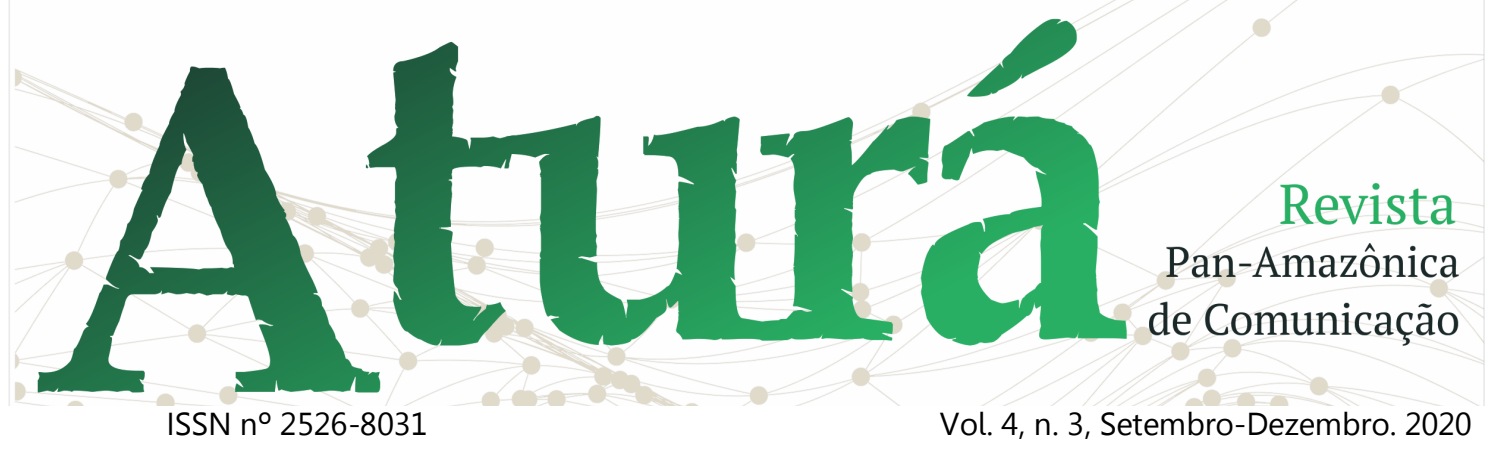

\section{Introdução}

Para rememorarmos a implantação da televisão no Brasil é preciso falar de Chateaubriand. $\mathrm{O}$ empreendedor visionário Francisco de Assis Chateaubriand Bandeira de Melo era nordestino. $\mathrm{O}$ balconista trocou o metro e a tesoura para realizar o sonho de trabalhar em um jornal: A Gazeta, que fechou as portas em 1907.

De volta ao jornalismo, em 1918 assumiu a direção do Jornal do Brasil. Três anos depois passou a ser correspondente internacional do Correio da Manhã, na Alemanha, escreveu um livro sobre o país alemão. No ano seguinte, 1922, Chatô comprou o seu primeiro jornal e passou a ter uma relação de proximidade com Getúlio Vargas - que se empolga com a ideia de Chateaubriand de criar uma rede de jornais. Em 1925, com o sucesso consolidado do "Jornal", Chateaubriand ampliou os negócios, e comprou em São Paulo, o "Jornal da Noite", por menos da metade do que estava sendo oferecido. $E$, pelas folhas dos jornais impressos que
Chatô passou, de acordo com seus interesses, a influenciar a opinião pública (KNEIPP, 2008).

Nas duas décadas e meia seguintes, se casa, se separa, tem uma filha fora do casamento, se envolve em guerras políticas. Chega a ficar foragido e viver na clandestinidade e ainda a ficar três meses preso em um presídio de São Paulo depois de publicar uma matéria em que pedia a anistia aos exilados. Reconstruiu seu império de comunicação e queria expandir. E assim o fez nos anos de 1950.

Os Diários e Emissoras Associadas se voltaram para TV. Em mais uma jogada aventureira, Assis Chateubriand decidiu trazer os técnicos norte-americanos da RCA para implantar a televisão no Brasil. Importou também os equipamentos; uma antena foi instalada no alto do edifício do Banco do Estado de São Paulo para retransmitir as imagens que viriam dos estúdios montados no prédio dos Diários Associados. (PATERNOSTRO, 1999, p. 28)

Foram várias fases de testes, até que no dia 18 setembro daquele mesmo ano, durante a inauguração da então PRF3 TV Difusora - que depois passou a se chamar TV Tupi - ocorreu a primeira transmissão, pelo canal 3, a partir do 


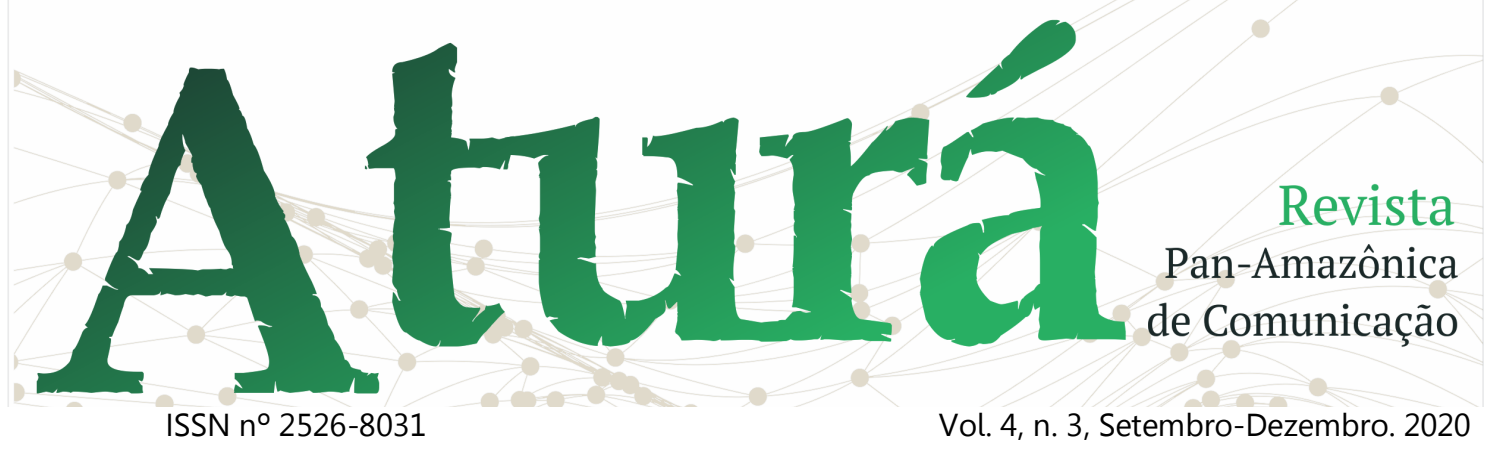

modelo desenvolvido nos Estados Unidos na década de 1940. A estreia da emissora pioneira da América Latina foi compartilhada com poucos. Havia, na época, apenas duzentos aparelhos distribuídos em praças e vitrines de lojas no centro de São Paulo. $O$ alcance do sinal também era limitado: cem quilômetros.

A estreia foi tumultuada, com atraso e a base do improviso. Uma das câmeras instaladas nos estúdios no Palácio do Rádio, quebrou e o técnico, norte-americano - que cuidava dos equipamentos - não estava no local. Os telespectadores tiveram que aguardar 40 minutos até que a 'TV na Taba' entrasse para a história como o primeiro programa transmitido ao vivo por uma emissora de TV. O espetáculo, que teve duas horas de duração, foi comandado por Cassiano Gabus Mendes, com direção artística de Dermival Costa Lima e contou com artistas como Mazzaropi, Walter Forster, Lia de Aguiar, Hebe Camargo, Lima Duarte, Wilma Bentivegna, Lolita Rodrigues, entre outros - "estava dada a largada! A TV brasileira era uma realidade" (PATERNOSTRO, 1999, p. 29).

Apesar do espírito premonitório de Chatô,
até meados da década de 1950, o
investimento na televisão era objeto de
desconfiança por parte dos anunciantes.
Em seus primórdios, a produção e a
distribuição televisiva resumiam-se ao
eixo Rio - São Paulo, estendendo-se, em
1955 a Belo Horizonte e, em 1959, a
Porto Alegre. Portanto, seu raio de ação
era limitado, não só pelo número
reduzido de telespectadores, como
também pela incipiente organização
empresarial e pelas limitações
tecnológicas do país. (SANTOS, 2015, p.
48-49)

O fundador e responsável pela chegada da televisão ao Brasil - Assis Chateaubriand - morreu no dia 4 de abril de 1968, de colapso nervoso. Chatô criou e dirigiu a maior cadeia de imprensa do país: foram 34 jornais, 36 radioemissoras, 18 estações de televisão, uma agência de notícias, uma revista semanal (O Cruzeiro), uma mensal (A Cigarra), várias revistas infantis e uma editora (SANTOS, 2015).

Este artigo tem como objetivo fazer um resgate histórico do telejornalismo tocantinense, mesmo antes da criação do Estado, refazendo a trajetória da implantação de emissoras 


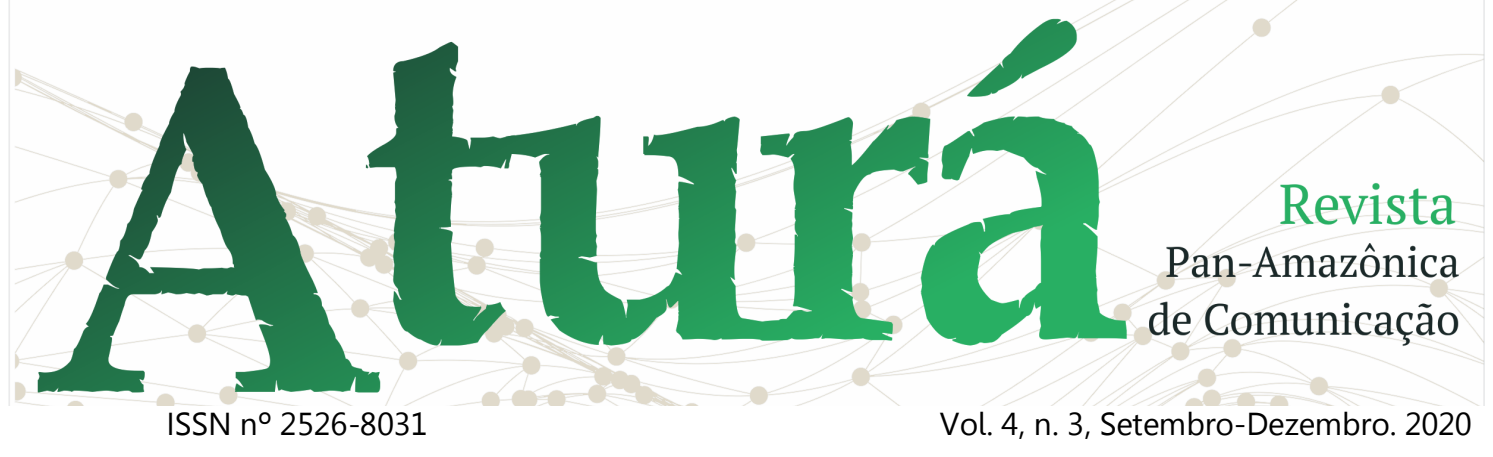

com ênfase à Rede Anhanguera de Televisão - Goiás/Tocantins. Os desafios vencidos pela ousadia de levar o sinal da emissora para uma parcela da população que vivia distante dos grandes centros. Como métodos foram adotadas análises qualitativas de informações coletadas e pesquisas (documental e bibliográfica).

\section{Os primeiros telejornais na década de} 1950

A televisão continuou com o processo de expansão. Uma nova emissora, ainda do grupo de Chateaubriand, foi aberta no Rio de Janeiro, em 1951. Naquele ano estimavase que já eram cerca de sete mil, o número de aparelhos, distribuídos, basicamente entre o Rio de Janeiro e São Paulo. No final daquela década seriam 200.000 televisores.

$\mathrm{O}$ primeiro telejornal surgiu junto com a chegada da TV ao Brasil. As notícias, em formato de grandes textos e poucas imagens, eram lidas por locutores - já que não existia a figura do jornalista apresentador - e as imagens exibidas nas reportagens eram extraídas de sobras do cinema, de documentários e, na maioria das vezes, essas imagens serviam para ilustrar situações, notícias que realmente estariam acontecendo, como enchentes, incêndios, por exemplo.

Chatô, embora fosse um conversador em
muitos sentidos, percebia que o futuro da
mídia apontava para a centralidade da
televisão. Assim como nos filmes
cinematográficos, as imagens da televisão
permitem materializar realidades e valores
distantes pelas imagens, manifestando
seu caráter de educador informal. Mais do
que isso, as imagens permitiam ampla
manipulação e "construção" de realidades
pautadas em objetivos econômicos e
políticos. (CASTRO, 2011, p. 54)

O primeiro telejornal foi o "Imagens do Dia" - sem tempo específico de produção - era apresentado por Maurício Loureiro Gama, ao vivo, e com entonação radiofônica. A transmissão ocorreu no dia 19 de setembro de 1950 um dia depois da inauguração da TV. As imagens eram produzidas em filme $16 \mathrm{~mm}$, preto e branco e o telejornal reproduzia o modelo de noticiar herdado do rádio. "O locutor lia as notícias em quadro (notas ao vivo). As imagens filmadas pelos cinegrafistas (quando existiam) eram apresentadas enquanto $o$ 


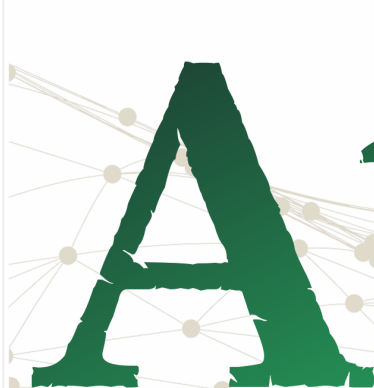

ISSN n $2526-8031$

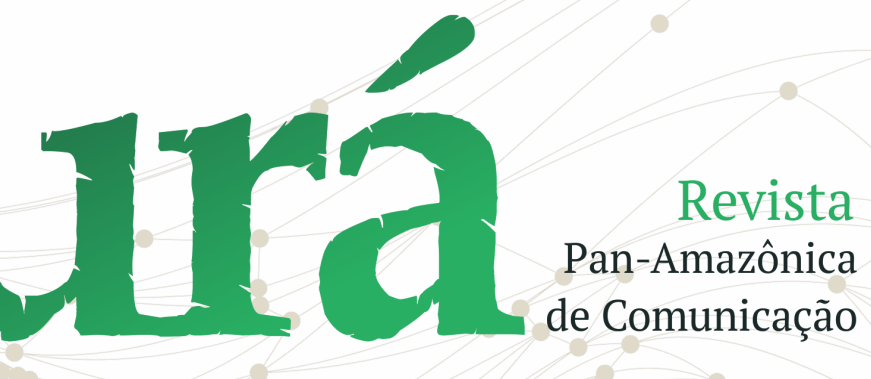

Vol. 4, n. 3, Setembro-Dezembro. 2020 locutor, ao vivo, narrava os acontecimentos" (MELLO, 2014, p. 315).

Quanto à linguagem audiovisual, segundo aponta Mello (2014), o telejornal Imagem do Dia teria sofrido uma marcante influência do cinejornal - na maneira de apresentar os acontecimentos aos telespectadores. É importante salientar que os cinejornais eram telejornais exibidos nos cinemas antes da exibição do filme em cartaz naquele dia e esses telejornais apresentavam as notícias que tinham ganhado destaque naquela semana. Imagens feitas em planos abertos, direto, com quase nenhuma edição, acompanhado pela narração do locutor, estilo off (MELLO, 2014).

O pioneirismo do telejornalismo brasileiro não contou com um aporte técnico que atendia todas as necessidades e exigências para exibir imagens de qualidade sobre o que se reportava, era o locutor apresentador quem acaba tendo lugar de destaque dentro do noticiário.

Ele era o principal elemento legitimador do telejornal, era ele quem mostrava o rosto e a voz, que emprestava o seu reconhecimento profissional para dar validade ao discurso das notícias. A imagem do locutor de notícias trajado com terno e gravata, e principalmente a sua Voz, eram utilizados como recursos retóricos e legitimadores, funcionando como ferramentas de persuasão que convenciam o telespectador de que a notícia era verdadeira. (MELLO, 2014, p. 317)

O avanço da tecnologia ajudou nas primeiras transformações do telejornalismo - ainda na década de 1950. A chegada do videoteipe, um gravador de imagens com fitas magnéticas, possibilitou que as reportagens fossem gravadas, editadas, assistidas e, se necessário, reeditadas antes de ir ao ar, fazendo com que os erros e falhas fossem evitados nos improvisos. É importante destacar que os primeiros equipamentos eram pesados, dificultando a locomoção nas gravações externas.

A transmissão de um mesmo telejornal para atuar em rede, ao vivo, aconteceu no dia primeiro de setembro de 1969 para seis cidades: Rio de Janeiro, São Paulo, Belo Horizonte, Curitiba, Porto Alegre e Brasília - segundo Maia (2011) através do sistema de satélite construído com recursos do Fundo Nacional de 


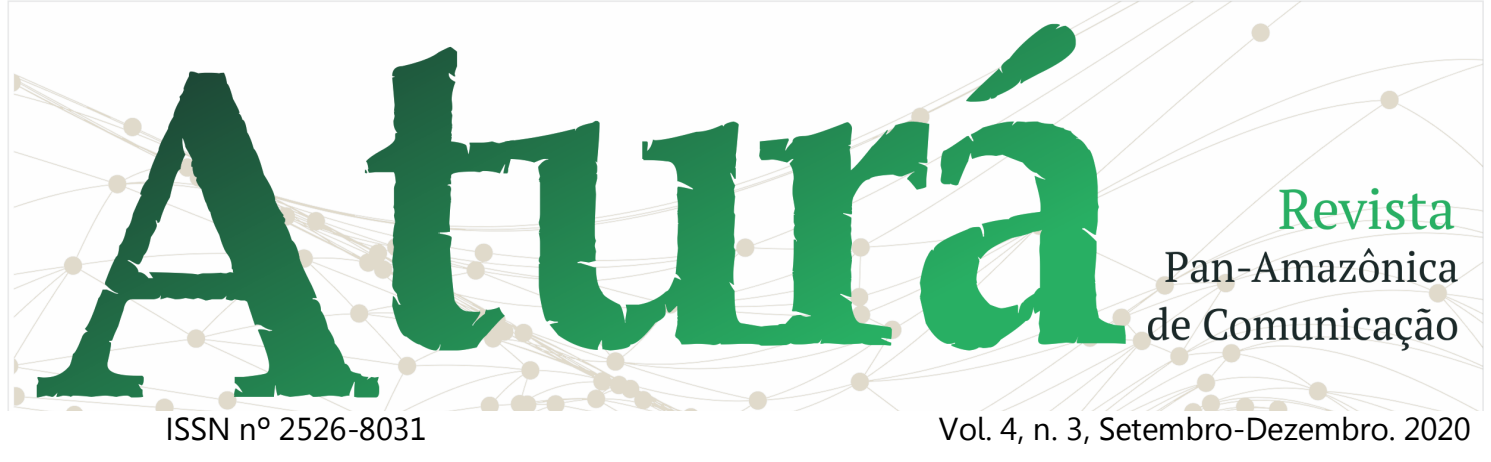

Telecomunicações. A página Memória Globo, a estreia do Jornal Nacional, da Rede Globo de Televisão, ocorreu às $19 \mathrm{~h} 45 \mathrm{com}$ os seguintes dizeres lidos pelos apresentadores do Hilton Gomes e Cid Moreira.

Novas mudanças começaram a ocorrer no telejornalismo brasileiro a partir da década de 1970. Com a inovação tecnológica as emissoras passaram a investir em câmeras portáveis que utilizavam o sistema U-Matic - a câmera era interligada por um cabo a uma espécie de vídeo cassete que ficava em estojos feitos de couro - para facilitar o transporte. Eram necessários dois operadores. Um cinegrafista e mais um auxiliar para carregar esse estojo interligado por cabos de áudio e vídeo. Essa integração dos aparelhos era chamada de ENG (Eletronic News Gathering) ou UPJ (Unidade Portátil de Jornalismo). Isso deixou as gravações de externa mais dinâmicas e facilitou a mobilidade das equipes deixando mais ágeis o registro dos acontecimentos dos fatos em diversas partes do mundo (SILVA, 2018).

\section{A chegada da TV no antigo Norte Goiano}

Não demorou muito para que as emissoras de TV buscassem retransmitir o sinal para o maior número de cidades possível. E apesar de controlar o que seria veiculado ou publicado na imprensa, o regime militar, que vigorou entre os anos de 1964 e 1985, ajudou nesse processo. Para Leal (2009), ao adotar a postura de integração nacional, com um governo focado para defender a segurança nacional e o desenvolvimento nacional baseados na industrialização e no crescimento econômico, os veículos de comunicação eram usados como portavozes oficiais do governo. Mais um motivo para facilitar a expansão desses meios. A ditadura militar contribuiu para o
impulso no desenvolvimento da TV no
Brasil, ao criar vários órgãos estatais que
lidavam com a produção cultural, ao
formular leis e decretos, ao congelar as
taxas dos serviços de telecomunicação, ao
dar isenção das taxas de importação para
compra de equipamento, ao proporcionar 


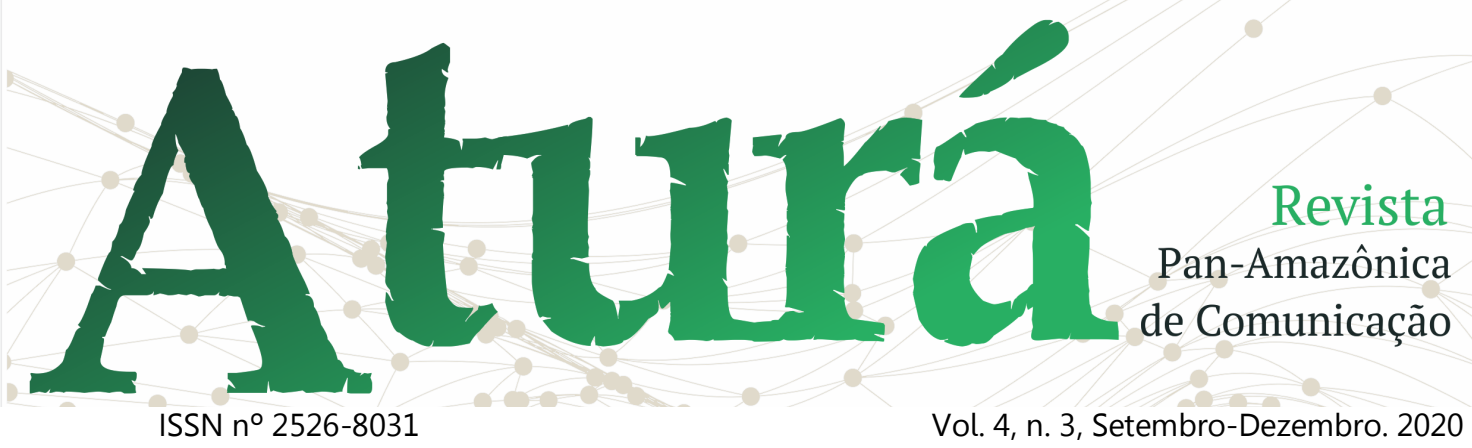

uma construção de uma estrutura nacional de telecomunicações em redes e ao fazer uma política de crédito facilitado. (LEAL, 2009, p. 8)

\section{O Regime Militar oferecia} incentivos fiscais para os empresários que investissem na Região Amazônica. E, segundo Santos (2015), foi assim que a Organização Jaime Câmara, atual Grupo Jaime Câmara, decidiu levar a TV Anhanguera ao antigo Norte goiano, hoje Tocantins. A TV Anhanguera foi fundada em Goiânia, em 1963, e se tornou uma das primeiras emissoras afiliadas da Rede Globo de Televisão.

A expansão começou por Araguaína, a maior cidade da região, distante cerca de 1.200 quilômetros da capital goiana. Mas a implantação da tv foi cercada de desafios, já que, na maioria dos municípios, não havia uma rede de energia permanente e a ligação de uma ponta a outra do Estado de Goiás, era literalmente na terra, já que a BelémBrasília, BR-153, não era asfaltada (SANTOS, 2015).

Mesmo com as condições adversas, o jornalista e empresário deu início nas tratativas de instalação da antena para retransmitir o sinal da TV Anhanguera em Araguaína. A iniciativa, de expandir o sinal da emissora pela região isolada, do antigo Norte goiano, contou com o apoio de políticos, que não economizavam nas homenagens públicas e discursos empolgados, como o que ocorreu na inauguração da mais nova sede da OJC em Araguaína. A solenidade contou com a participação do Secretário Geral de Radiodifusão do Ministério das Comunicações - Lourenço Scherad e da Diretora Substituta Regional do Dentel, Messias Joselina Curado que fez um pronunciamento de exaltação ao empresário Jaime Câmara.

A emissora entrou oficialmente no ar no dia 10 de dezembro de 1976, uma sexta-feira, levando o sinal para sete cidades do extremo norte goiano, além de duas no Maranhão, com uma programação gravada na capital, Goiânia, e com imagens coloridas para cerca de três mil receptores.

A mais recente retransmissora do Canal 2, em Araguaína, foi equipada com 


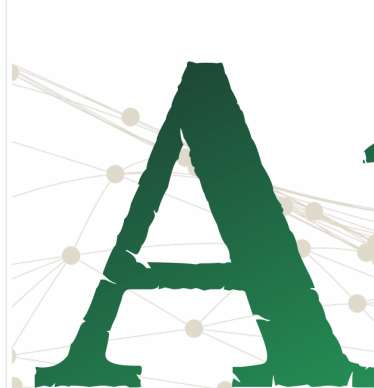

ISSN n² 2526-8031

\section{Revista}

Pan-Amazônica

de Comunicação

Vol. 4, n. 3, Setembro-Dezembro. 2020

o que havia de mais moderno na época, em prédio próprio, com torre e antenas de alto ganho. A tecnologia era capaz de levar som e imagens para as cidades de Colinas de Goiás (hoje, Colinas do Tocantins), Axixá (do Tocantins), Tocantinópolis, Araguanã, Guaraí, Wanderlândia, Filadélfia e ainda Carolina e Porto Franco, ambos municípios do estado vizinho, Maranhão. Ainda na fase de testes da TV Anhanguera em Araguaína houve uma grande vendagem de aparelhos a cores e preto e branco na cidade.

A solenidade de inauguração foi regada a um banquete oferecido para cem convidados que estavam ali representando famílias importantes, autoridades políticas, eclesiásticas e civis organizadas.

Estávamos isolados e agora estamos integrados ao Brasil através das comunicações mais avançadas, que é a televisão. Poderemos, agora, além de ver o Jornal Nacional, assistir a bons filmes e novelas, ouvir as palavras do Presidente Geisel e do Governador Irapuan Costa Júnior, em suas mensagens ao povo brasileiro. Consideramos a história da região antes e depois da televisão e da Belém-Brasília e, por isso, agradecemos ao jornalista Jaime Câmara, que acreditou no progresso e no desenvolvimento de
Araguaína. O senhor pode acreditar que os moradores desta região saberão apoiálo sempre nas suas iniciativas. (O Popular, $1976^{2}$ )

Apesar de enaltecido o pioneirismo, aquela não teria sido a primeira retransmissora de Araguaína. Santos (2015) afirma que um grupo de entusiastas da televisão, formado por moradores nortistas de várias cidades, criou a comissão pró-TV, e arrecadou dinheiro e até um carro zero, para ir à São Paulo comprar equipamentos suficientes para montar cinco torres, cada uma com trinta metros de altura, além de baterias, carregadores e motores que pudessem gerar energia em cinco cidades, incluindo Araguaína. As repetidoras recebiam a programação que era gravada em fitas em Imperatriz, no Maranhão, e enviadas diariamente por ônibus interestaduais.

Em Araguaína a torre foi erguida na Avenida Cônego João Lima na estação que foi apelidada com o nome da cidade - TV Araguaína, mas não durou muito

\footnotetext{
2 Discurso do Juiz de Direito de Araguaína, João Batista Neto, extraído da reportagem 'Canal 2 de Araguaína já chega a 9 cidades', publicada no O Popular, Goiânia, 14 de dezembro de 1976, p. 6.
} 


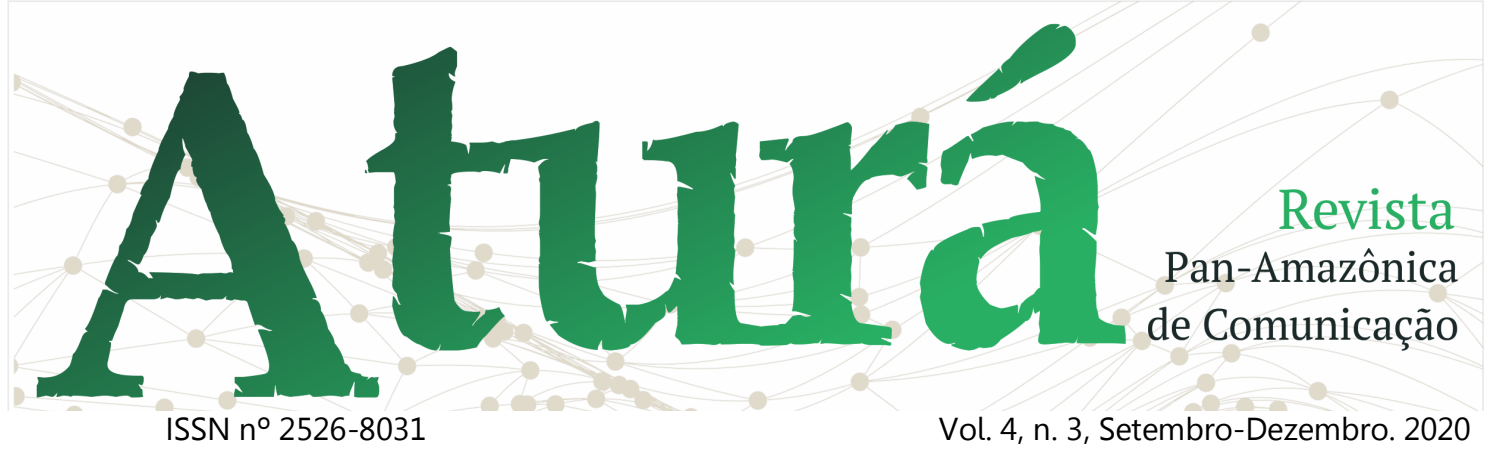

tempo. "Nem chegou a ser autorizada pelo Governo Federal pois, segundo seus articuladores, o processo de concessão foi barrado com a chegada do Grupo Jaime Câmara" (SANTOS, 2015). Na época, Santos (2015) destaca que os padrões de administração das emissoras brasileiras seguiam normas americanas e metade das programações era feita de filmes estrangeiros. A retransmissora exibia programas copiados de uma emissora maranhense e mesmo assim despertou interesses de políticos locais e nacionais, como o Senador Benedito Ferreira, conhecido como Benedito Boa Sorte, mas essas mesmas lideranças, incluindo o Senador, passaram a apoiar o empresário Jaime Câmara que contara com quase dez anos de experiência no ramo da comunicação, incluindo a concessão de um canal de TV.

Santos (2015) afirma que para receber apoio, Jaime Câmara fez uma verdadeira campanha de marketing para convencer lideranças empresariais e políticas, incluindo a distribuição de aparelhos de televisão. E já na fase de testes, a qualidade da imagem ajudou nesse convencimento. $\mathrm{O}$ empresário também recebeu ajuda dos próprios moradores, que chegaram a doar o terreno, onde até hoje funciona a sede da emissora em Araguaína.

A participação de apoiadores foi decisiva para que a própria prefeitura de Araguaína, segundo Santos (2015), abrisse crédito a partir do Projeto de Lei n. ${ }^{\circ} 73$ de 27 de dezembro, que foi aprovado duas semanas após a inauguração da retransmissora da TV Anhanguera na cidade, beneficiando diretamente a empresa de Jaime Câmara. Depois de passar na Câmara Municipal, o prefeito Wilson Gomes de Sousa sancionou a lei da concessão de ajuda especial de Cr\$100.000,00 (Cem mil cruzeiros) destinada à implantação do sistema de som e imagem de televisão da cidade.

A venda de aparelhos aqueceu $\mathrm{o}$ comércio e o coração grato de políticos. Em 1978 a Câmara Municipal aprovou voto de louvor para a Organização Jaime Câmara por ter se esforçado para levar 


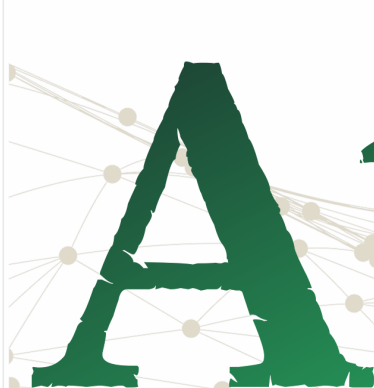

ISSN n $2526-8031$
Revista

Pan-Amazônica

de Comunicação

Vol. 4, n. 3, Setembro-Dezembro. 2020

imagem e som pelo Canal 2 e chegou a assumir estar constrangida por não poder ajudar mais. No ofício disseram que "sentem-se desconcertados por não poderem dispor de maiores meios para expressar a sua gratidão para com o seu preclaro concidadão (referindo-se ao empresário Jaime Câmara)" (SANTOS, 2015).

E os elogios em público e nas solenidades continuaram. No mesmo ano, durante a visita do General João Batista Figueiredo, o prefeito Joaquim de Lima Quinta, fez cobranças ao então Presidente da República para que fossem feitos investimentos na infraestrutura da cidade e, no mesmo discurso, destacou o pioneirismo do grupo chefiado por Jaime Câmara, fazendo referência ao que ele considerou como espírito empreendedor, gerando aplausos e gritos de apoio.

E aqui eu quero abrir um parêntese, para cumprimenta o Grupo Jaime Câmara através de seu Diretor Jaime Câmara Júnior, que é uma dai coisas que mais nos ajudaram ultimamente é a sua televisão. A televisão trouxe para o povo do Norte informações atuais de tudo que se passa no país e no mundo. Ao Jaime Câmara, ao Grupo Jaime Câmara pela assistência que tem dado ao nosso povo. A este grupo nós queremos render ainda uma homenagem especial porque temos certeza de que dentro em breve será instalada aqui em Araguaína a Rádio Anhanguera, que se Deus quiser ir cobrir não somente o Norte de Goiás, mas toda a nossa extensão territorial. Pois a obra pioneira deste importante tem contribuído decisivamente para a integração desta vasta região e para o desenvolvimento da nossa gente, porque aqui ele implantou a informação atual, a educação, a cultura e o entretenimento. (O Popular ${ }^{3}$, 1978).

A expansão do Canal 2 chegou a Gurupi, até então cidade localizada na região Centro Norte de Goiás e com projetos de expansão do sinal. Em 1978, a partir da formação do Consórcio de Televisão Médio Norte Goiano, uma iniciativa das prefeituras de Paraíso do Norte (atual Paraíso do Tocantins), Cristalândia, Pium e Porto Nacional foram anunciadas medidas para que o som e a imagem da TV Anhanguera Canal 2 chegassem até a essas cidades. $O$ investimento foi orçado em $\mathrm{Cr} \$$ 2.601.788,00 (dois milhões, seiscentos e um mil e setecentos e oitenta e oito cruzeiros), desse total, Cr\$ 910.968,00 (novecentos e dez mil e novecentos e

\footnotetext{
3 Trecho do discurso do prefeito de Araguaína, Joaquim de Lima Quinta, extraído do O Popular, Goiânia, 10 de novembro de 1978, p. 4)
} 


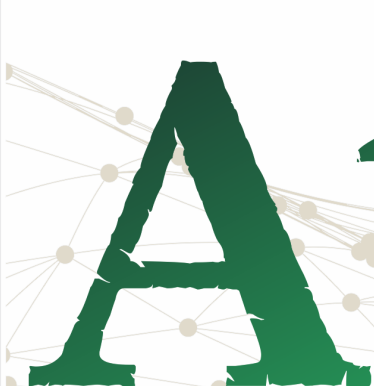

ISSN n² 2526-8031
Revista

Pan-Amazônica

de Comunicação

Vol. 4, n. 3, Setembro-Dezembro. 2020 sessenta e oito cruzeiros) seriam destinados para a compra de equipamentos. O restante seria aplicado nas obras de infraestrutura de acessórios de transmissão de TV, e de energia e custos de instalação ${ }^{4}$.

Em junho daquele mesmo ano o Canal 2 já podia ser acompanhado pelos moradores de Porto Nacional, Cristalândia, Pium, Paraíso do Norte (do Tocantins) e Brejinho de Nazaré. A chegada do sinal nessas cidades rendeu homenagens do Poder Legislativo do Estado de Goiás. A Assembleia Legislativa, através do requerimento do deputado Wilton Cerqueira e dos parlamentares Juracy Teixeira e Antônio Pereira, fez menção honrosa para o empresário Jaime Câmara.

Apesar de representar um marco histórico e de grande importância para uma população que vivia no isolamento, o progresso e crescimento da chegada da TV Anhanguera, também atendia interesses políticos e trocas vantajosas. Santos (2015) afirma que para o então

\footnotetext{
${ }^{4}$ Jornal O Popular, de 29 de janeiro de 1978.
}

prefeito de Araguaína, João Ribeiro, "a televisão proporcionaria oportunidades de veiculação de propaganda política, divulgação de projetos da prefeitura" (SANTOS, 2015), permutando dividendos do Paço Municipal em troca de ações publicitárias televisivas das ações do poder público municipal.

No início da década de 1980 a Organização Jaime Câmara manteve os investimentos na ampliação e melhoramento do sinal transmitido pelo Canal 2 em Araguaína e em Gurupi com a assinatura dos contratos de concessão para as duas emissoras: TV Anhanguera de Araguaína e TV Rio Formoso de Gurupi, que deixaram de ser repetidoras e passaram a ser geradoras. As duas concessões foram outorgadas pelos decretos presidenciais 87.534 e 87.535, assinados dia 30 de agosto de 1982. O anúncio aconteceu em uma cerimônia presidida pelo ministro Haroldo Corrêa de Matos, que afirmou que aquele momento era demonstração pública e cabal de confiança do presidente João Figueiredo na Organização Jaime Câmara. 


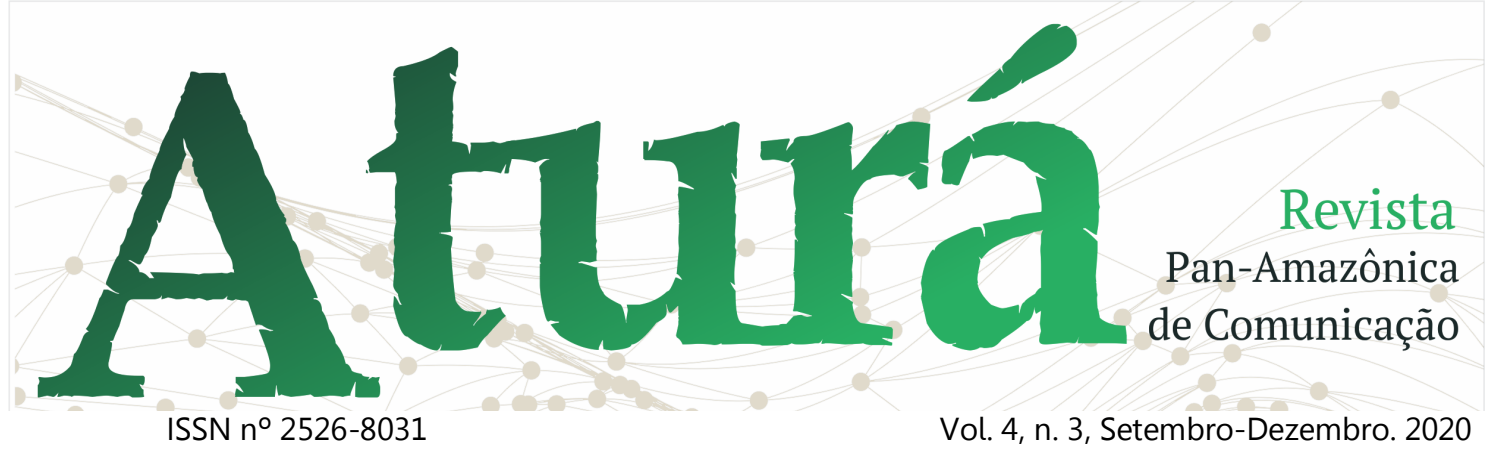

Jaime Câmara Júnior, filho de Jaime Câmara, na oportunidade, anunciou que as emissoras de Goiânia, de Gurupi e de Araguaína seriam ligadas ao satélite e revelou o esforço empreendido da OJC para expandir as atividades ao extremo norte do Estado integrando Goiás, pelas telas da TV. A íntegra do discurso foi publicada na reportagem 'TVs de Araguaína e Gurupi têm contrato', no O Popular, de 20 de outubro de 1982, página 9.

Ainda durante 0 discurso, 0 presidente da TV Rio Formoso, Jaime Câmara Júnior, enfatizou as dificuldades de acesso e os custos financeiros para transportar o sinal a uma distância de 1.200 quilômetros entre a capital Goiânia e a cidade de Araguaína, localizada no Norte do Estado. Na época estavam sendo experimentadas as repetidoras assíncronas, que funcionavam com vídeo cassetes e com a programação defasada em alguns dias da estação geradora. Apesar disso, disse que assumiu um compromisso de entregar e atender as

regiões Centro-Oeste e Norte, prestando um serviço de qualidade.

O discurso encerrou destacando os avanços de expansão da Organização Jaime Câmara através das estações da TV Anhanguera de Goiânia, da TV Tocantins de Anápolis, e agora da TV Rio Formoso de Gurupi e TV Anhanguera de Araguaína, que passavam a contar com 2.500 quilômetros de links em VHF sendo transmitidos, a partir do dia 30 de outubro de 1982 via satélite interligando Goiânia, Gurupi e Araguaína e integrando a população destas regiões à era da comunicação.

\section{A multiplicação das antenas de transmissão pelo Tocantins}

A região que passou a ter opções de canais com o passar dos anos recebendo novos investimentos na área da mídia televisiva. A TV Brasil Central, afiliada à Rede Bandeirantes, que pertencia ao Governo do Estado de Goiás - através do Consórcio de Empresas de Radiodifusão e Notícias do Estado - 


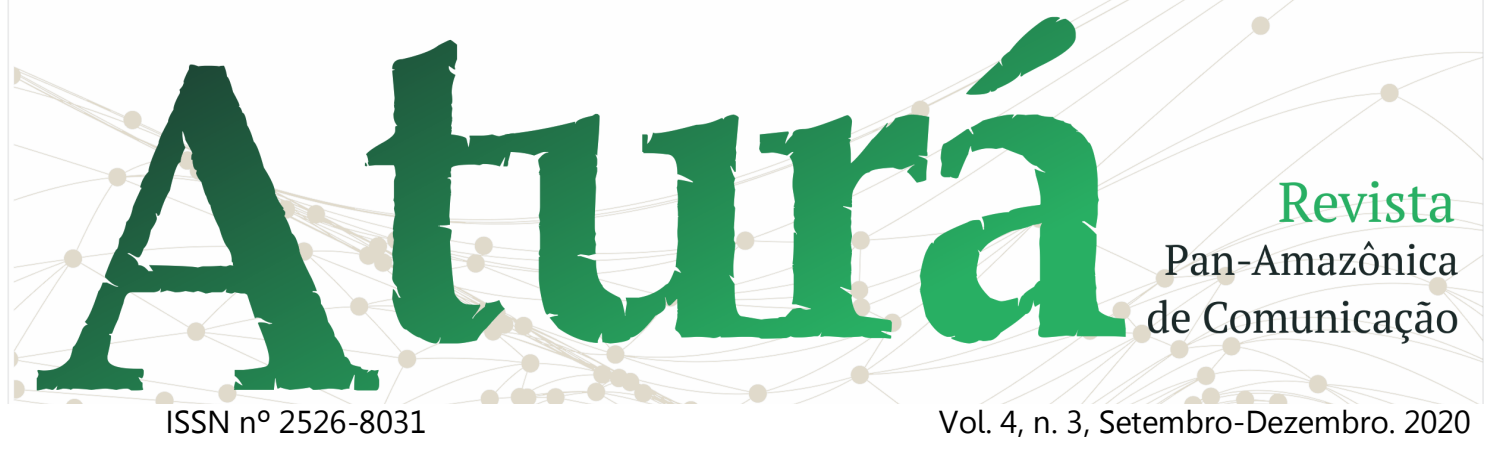

CERNE, foi instalada no início de 1982 e contava com retransmissoras em

Franco (TV Difusora) e Imperatriz (TV Nativa) (ROCHA; SOARES: ARAÚJO, 2014, p. 175)

Araguaína e em Gurupi. Depois da criação do Tocantins surgiu a Companhia de Comunicação do Estado do Tocantins COMUNICATINS.

De acordo com Rocha, Soares e Araújo, (2014) a Comunicatins era uma empresa de direito privado, com economia mista, tendo o Governo do Tocantins, como principal acionista. Em 1996, a emissora se transformou em autarquia e passou a se chamar Instituto Dom Alano, atuando com a Universidade do Tocantins - UNITINS com a finalidade de explorar a prestação de serviços de Rádio e TV, mas a falta de recursos provocou uma nova mudança.

No ano seguinte, devido à falta de recursos e objetivando regularizar legalmente o serviço de radiodifusão sob a tutela do Estado, o Instituto é transformado na Fundação Unitins, autarquia com autorização para executar o serviço com fins educativos. Este processo gerou a Rádio Palmas 96,1 FM, que entrou no ar em 2000 em caráter experimental; e a TV Palmas, com transmissões a partir de 2003, que tempos depois passou a se chamar Rede Sat e mais recentemente TVE Tocantins. Ampliando o arco regional, a TV estatal tem sinal captado por 10 municípios maranhenses limítrofes, como Porto

\footnotetext{
5 TV Pública do Tocantins não terá mais programação local; Rádio continua funcionando. In: G1 Tocantins. [S. l.], 2 jan. 2019. Disponível em: https://g1.globo.com/to/tocantins/noticia/2019/01/02/t v-publica-do-tocantins-nao-tera-mais-programacaolocal-radio-continua-funcionando.ghtml. Acesso em: 15 fev. 2020.

6 SERVIDORES Públicos fazem protestos pela permanência da RedeSat, Jornal do Tocantins. In: Jornal do Tocantins. [S. l.], 3 jan. 2019. Disponível em: https://www.jornaldotocantins.com.br/editorias/noticias /servidores-p\%C3\%BAblicos-fazem-protesto-pelaperman\%C3\%AAncia-da-redesat-1.1697916. Acesso em: 15 fev. 2020.

7 TV Cultura afilia-se com a TV Educativa de Tocantins. In: TV CULTURA. [S. l. $], 22$ fev. 2019. Disponível 


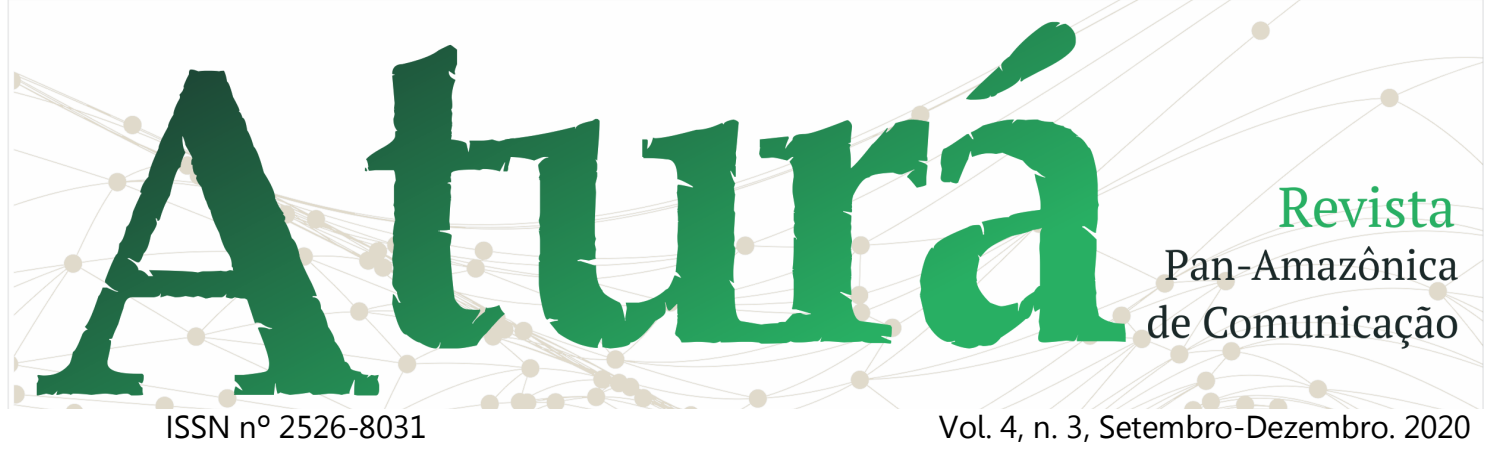

retransmitir o sinal pelo canal 13.1. O acordo garantiu a expansão do alcance da TV pública paulista para mais 350 mil telespectadores, de oito municípios tocantinenses que antes não tinham acesso ao canal.

Outras emissoras não tiveram o mesmo desfecho e acabaram encerrando as atividades em definitivo por diversos motivos. De acordo com o Sistema Mosaico $^{8}$ da Agência Nacional de Telecomunicações (Anatel) a TV Girassol de Gurupi, afiliada da Band, fechou as pontas em 2015. Isso aconteceu depois de uma ordem judicial de reintegração de posse (TV..., 2015) ${ }^{9}$. Na decisão, o juiz

https://tvcultura.com.br/acontece/808_tv-cultura-afiliase-com-a-tv-educativa-de-tocantins.html. Acesso em: 15 fev. 2020.

8 O Sistema Mosaico é uma plataforma com vários módulos voltados aos diversos serviços de telecomunicações e radiodifusão. O módulo Sistema de Cadastro de Radiodifusão (SCR) é utilizado para manutenção de cadastros de estações de radiodifusão. Os únicos serviços não contemplados pela ferramenta são Ondas Curtas (OC), Ondas Tropicias (OT) e Radiodifusão Comunitária (RADCOM). Disponível em: https://www.mctic.gov.br/mctic/opencms/comunicacao/ SERAD/radiofusao/Sistemas/radiodifusao_sistemaMosai co.html. Acesso em: 15 fev. 2020.

${ }^{9}$ TV Girassol, retransmissora da Band, encerra produção local em Gurupi. In: Atitude Tocantins. [S. l.], 26 maio 2015. Disponível

http://www.atitudeto.com.br/depois-de-palmas-bandencerra-producao-local-em-gurupi/. Acesso em: $15 \mathrm{fev}$. 2020.
Pedro Nelson de Miranda Coutinho, da Terceira Vara Cível da Comarca de Palmas, mandou a empresa restituir bens, incluindo painéis de antena e transmissores por descumprimento de acordo contratual - a empresa foi arrendada por uma rede de comunicação da Igreja Mundial do Povo de Deus. A emissora ficou no ar por doze anos. Já a TV Central, afiliada da Rede RecordTV foi fundada e extinta no mesmo ano.

Em 2008 o Grupo Bandeirantes inaugurou em Palmas a primeira emissora própria na região Norte do país (GRUPO..., 2008) ${ }^{10}$. A Band Tocantins era comandada pelo jornalista Fernando Hessel e foi precedida pela TV Palmas, pela TV Javaés e pela TV Girassol. Em 2015 a emissora foi fechada e passou a retransmitir a programação nacional. (REIS; ROCHA, 2018).

\footnotetext{
10 GRUPO Bandeirantes inaugura nesta quarta em Palmas nova emissora; a Band Tocantins. Conexão Tocantins. In: Conexão Tocantins. [S. l.], 22 out. 2008. Disponível em: https://conexaoto.com.br/2008/10/22/grupobandeirantes-inaugura-nesta-quarta-em-palmas-novaemissora-a-band-tocantins. Acesso em: 15 fev. 2020.
} 


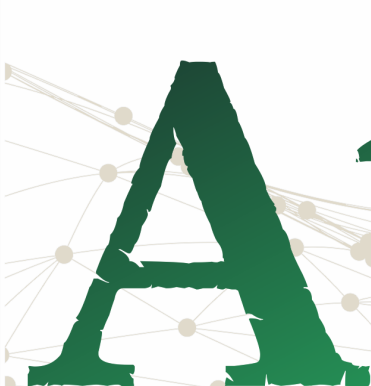

ISSN n² 2526-8031
Revista

Pan-Amazônica

de Comunicação

Vol. 4, n. 3, Setembro-Dezembro. 2020
Segundo o Sistema Moisaico da Anatel, desde que foi criado o Estado do Tocantins, pelo menos oito emissoras deixaram de existir em Palmas: TV Javés, TV Real, TV Central, TV Cristal, TV Lajeado, TV Serra do Carmo, Band Tocantins e TV Graciosa.

Quadro 1 - Emissoras que contavam com programações locais e que encerraram as atividades em Palmas

\begin{tabular}{|l|c|c|c|}
\hline \multicolumn{1}{|c|}{ EMISSORA } & CANAL & AFILIADA & PERÍODO \\
\hline $\begin{array}{l}\text { BAND } \\
\text { TOCANTINS }\end{array}$ & 4 & BAND & $\begin{array}{c}2008- \\
2015\end{array}$ \\
\hline $\begin{array}{l}\text { TV } \\
\text { CENTRAL }\end{array}$ & 5 & RECORDTV & 2006 \\
\hline TV CRISTAL & 5 & REDETV! & $\begin{array}{c}2000- \\
2007\end{array}$ \\
\hline TV \\
GRACIOSA & 4 & TV GAZETA & $\begin{array}{c}2016- \\
2018\end{array}$ \\
\hline TV JAVAÉS & 7 & TANDEIRANTES & $\begin{array}{c}1992- \\
1997\end{array}$ \\
\hline TV \\
LAJEADO & 2 & RECORDTV & $\begin{array}{c}1993- \\
2007\end{array}$ \\
\hline TV REAL & 5 & SBT & $\begin{array}{c}1992- \\
2000\end{array}$ \\
\hline TV SERRA \\
DO CARMO
\end{tabular}

Fonte: Anatel, [201-]

De acordo com o site Mapa da Mídia (NEPJOR/UFT), que traçou a trajetória da chegada das emissoras de TV no Tocantins, a primeira televisão a instalar-se em Palmas, capital do Estado, foi a TV Jovem Palmas, transmitindo, na época, o sinal do SBT, pelo canal 11 . No início de 2007 a empresa perdeu a concessão e ficou fora do ar por oito meses, retornando no dia sete de dezembro, mas dessa vez como afiliada da Rede Record. Já a transmissão do SBT, chegou a ficar na mão de outros dois grupos até que em 2015, o SBT Tocantins, sob nova administração, passou a comandar o canal.

Mas é a cidade de Araguaína, segundo a Anatel, onde mais se concentram emissoras de canais abertos de TV no Estado do Tocantins, com programação local. São sete emissoras: TV Alvorada (TV Gazeta), TV Amazônia (Band), TV Anhanguera (TV Globo), TV Araguaína (SBT), TV Aratins (Rede Meio Norte), TV Jovem Araguaína (RecordTV) e Rede Líder (RedeTV).

Essas emissoras investem em produção de conteúdo local, sejam em telejornais ou programas de entretenimento para discutir temas e assuntos de interesses diversos da população de Araguaína. Para Meneses (2010) a mídia local se constrói com base 


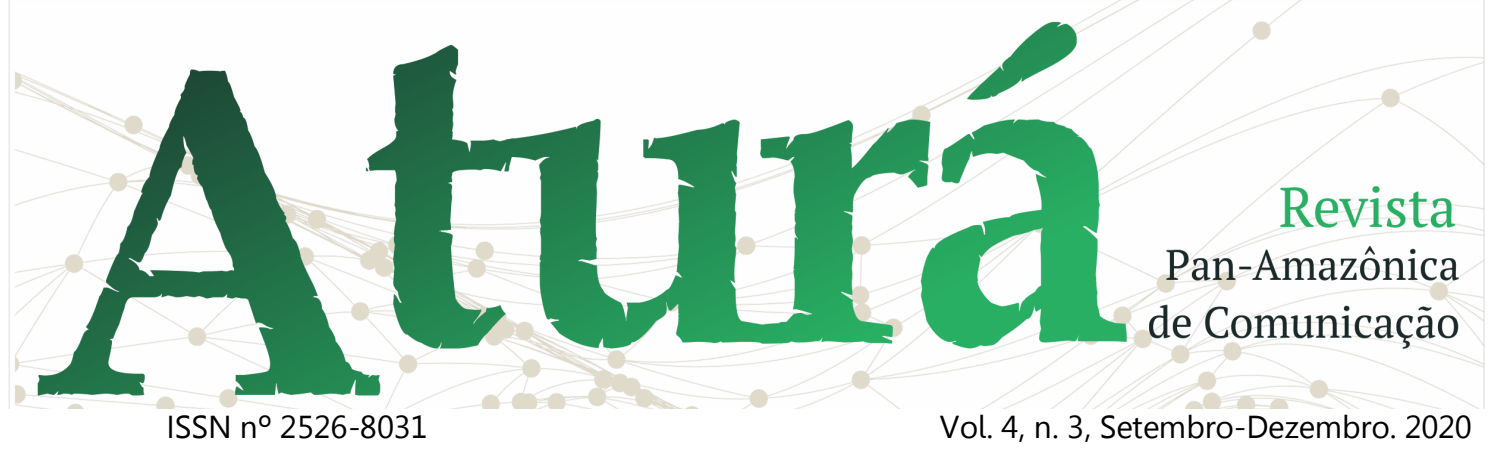

naquilo que se torna expressivo para a comunidade de determinado território.

s emissoras de TV são estruturadas pelo espaço geográfico, inclusive na definição do que seja "informação local", mas ao mesmo tempo supera este espaço na medida em que esta proximidade pode ser definida em relação à abrangência dos públicos de interesse. (MENESES, 2010, p. 63)

A última TV aberta a instalar-se em Palmas foi a RedeTV Tocantins, afiliada da RedeTV!, em 14 de março de 2019, já transmitindo o sinal digital pelo canal 29 UHF. Já a Tocantins TV foi a primeira emissora de televisão do Tocantins exclusivamente online. Segundo Reis e Rocha (2018), a emissora conta com equipamentos e tecnologia para transmitir, ao vivo e em tempo real, imagens com drone e 360 graus, pela página do Facebook, onde é postada toda a produção do canal. "O surgimento dessas mídias tem um forte entrelaço com a própria história do Tocantins; de sua criação, suas lutas, suas particularidades políticas, sociais e culturais, grande parte de tudo isso foi registrado por essas mídias". (REIS; ROCHA, 2018, p. 13)
Para Reis e Rocha (2018) o resgate da trajetória da televisão tocantinense revela-se uma tarefa importante de valor histórico e cultural para o Estado de pouco mais de três décadas de criação.

\section{Considerações finais}

A pesquisa traçou a trajetória da chegada da televisão no Estado do Tocantins, antes da divisão do Estado de Goiás. A força política teve contribuição decisiva para a expansão das torres, incluindo a doação de terrenos e a permuta de áreas por comerciais televisivos, como a chegada da Televisão Anhanguera em Araguaína.

Ressalta-se que apenas meia década depois da criação do Tocantins foi que as emissoras passaram a produzir programas locais, com informações exclusivamente regionais. $E_{\text {, apesar dos }}$ investimentos, muitas empresas de comunicação que ousaram abrir as portas, não se mantiveram no mercado, principalmente na capital.

\section{Referências}




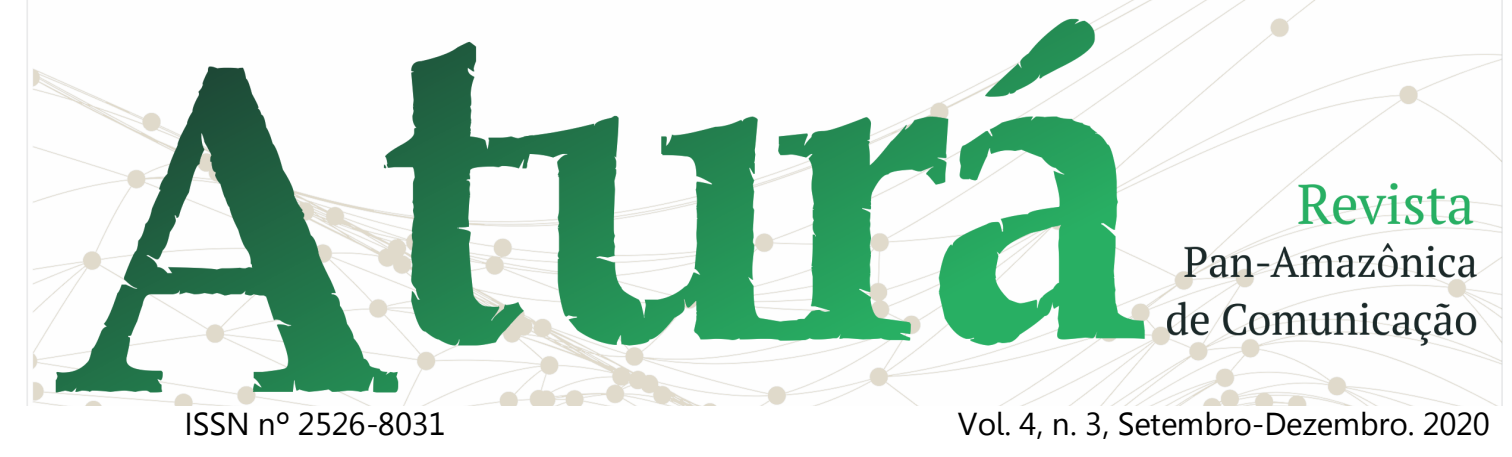

CASTRO, Nilo. A Televisão e Presidência da República: a soberania em disputa de 19501964. Tese (Doutorado em Ciência Política). Universidade Federal do Rio Grande do Sul, UFRGS, Porto Alegre. 2011, 322 f.

FONSECA, Adriano Nogueira da. O Telejornalismo no Tocantins em três momentos: linguagem, história e técnica. In: IV Jornada Interdisciplinar do PPGCOM/UFT Tendências em Comunicação: a construção social nas narrativas contemporâneas. Anais... PPGCOM/UFT: Palmas: 2019.

KNEIPP, Valquíria Passos. Trajetória de formação do telejornalista brasileiro. Tese (Doutorado em Comunicação) Universidade de São Paulo, USP, Escola de Comunicações e Artes - ECA, São Paulo, 2008, 245 f.

LEAL, Plínio. Um olhar histórico na formação e sedimentação da TV no Brasil. In: VII Encontro Nacional de História da Mídia, 2009, Fortaleza/CE. Anais... ALCAR: Fortaleza, 2009.

LINHA do tempo. A televisão no Tocantins. Disponível em: http://www.timetoast.com/timelines/1501011. Acesso em 20 fev 2020.

MAIA, Aline Silva Corrêa. O Telejornalismo no Brasil na Atualidade: Em Busca do Telespectador. In.: XVI Congresso de Ciências da Comunicação na Região Sudeste, São Paulo. Anais... Intercom: São Paulo, 2011.

MENESES, Verônica Dantas. Cenário da programação de TV regional aberta no Brasil: desafios e perspectivas. Tese (Doutorado em Comunicação) - Universidade de Brasília, Brasília, 2010, 362 f.

MELLO, Edna. Telejornalismo e história: permanências e rupturas no fazer jornalístico. In: VIZEU, Alfredo et tal. (Org.) Telejornalismo em questão. Florianópolis: Insular, 201. P. 309-328, 2014.

MELLO, Jaciara. Telejornalismo no Brasil. Universidade da Beira Interior. Covilhã: Portugal. 2009.

MEMÓRIA GLOBO. Vera Íris Pasternostro. Disponível em: https://memoriaglobo.globo.com/perfil/verairis-paternostro-2/._Acesso em: 20 Jan 2020.

MEMÓRIA GLOBO. Jornal Nacional. Disponivel em: http://memoriaglobo.globo.com/programas/j ornalismo/telejornais/jornal-nacional.htm.

Acesso em: 11 Jan 2020.

PATERNOSTRO, Vera Íris. O texto na TV: manual de telejornalismo. Rio de Janeiro: Elsevier, 1999.

REIS, Lys Apolinário; ROCHA, Liana Vidigal. Televisão e Mídias Sociais: a circulação de conteúdo da emissoras do Tocantins. In: $17^{\circ}$ Encontro Nacional de Professores de Jornalismo, 2018, Palmas. Anais... ABEJ: Palmas, 2018.

REIS, Lys Apolinário; SILVA, Edna de Mello. Televisão e história: uma proposta de linha do tempo da trajetória da mídia televisiva no Estado do Tocantins. In: XI Encontro Nacional da Associação Brasileira de Pesquisadores de História da Mídia, 2017, São Paulo. Anais... ALCAR: São Paulo, 2017.

ROCHA, L. V.; SOARES, S. R.; ARAÚJO, V. T. Abrangências locais no jornalismo online do Tocantins. Comunicação \& Inovação, São Caetano do Sul, v. 15, n. 29, p. 171-185, 2014.

SANTOS, Jocyleia Santana dos. A Sedução da Imagem: a televisão no limiar do Tocantins. Palmas: EDUFT, 2015. 


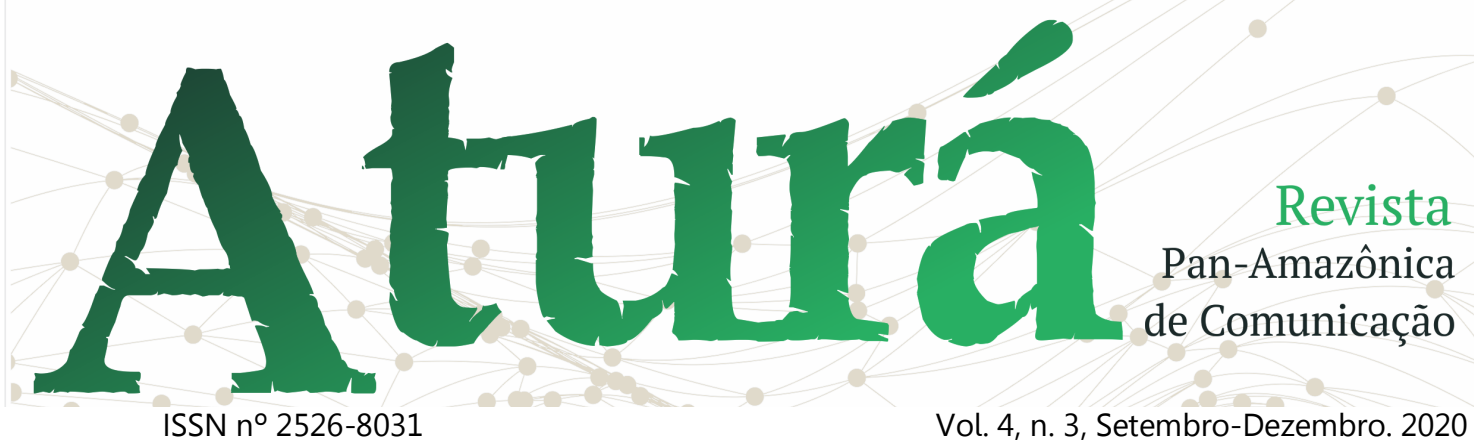

SILVA, Edna de Mello. Fases do

Telejornalismo: uma proposta epistemológica. In: EMERIM, Cárdila; COUTINHO, Iluska; FINGER, Cristiane (orgs.). Epistemologias do telejornalismo brasileiro. Coleção Jornalismo Audiovisual, v. 7. Florianópolis: Insular, 2018. 